\title{
Chapter 9 \\ The Experience of Being a Filipino Seafarer on a Multinationally Crewed Ship
}

\author{
Iris Acejo
}

\section{Introduction}

The globalised labour market for seafarers has led to multinationally crewed vessels. According to a study conducted by Seafarers International Research Centre in 2003, about $60 \%$ of ships have multinational crews (Ellis and Sampson 2003). A more recent study showed that $85 \%$ of vessels that call in ports in Finland have multinational crew mix and that two and three nationalities are the most prevalent crewing pattern (Storgård et al. 2013). The Philippines, is one of the world's biggest source of seafarers, as such it is worth considering the lived experiences of Filipino seafarers on multinationally crewed vessels.

It is common for Filipino seafarers to work on board under temporary contractual arrangements between 6 and 12 months, with 8 to 12 hour work days. Watchkeeping deck officers work 7 days a week, on a 'week in and week out' basis. Seafarers in other positions may have an occasional Sunday off when their vessel is not in port. Reduced opportunities for shore leave make the ship ever more confining in what is already a risky and uncomfortable environment. Accounts of how Filipino seafarers grapple with these contemporary realities can provide an insight into their day-today lives. This chapter explores the nature of Filipino seafarers' relationships within a multi-ethnic crew under temporary, fixed-wage employment and the strategies they adopt on board to survive in such working conditions. The results presented here consider the ways in which Filipino seafarers engage with, and assert themselves in, restrictive social spaces given the inter-workings of routines, hierarchies and nationalities on board. The way in which Filipino seafarers interact within a closely controlled environment reflects how the present structure of the shipping industry

\footnotetext{
I. Acejo $(\bowtie)$

Cardiff University, Seafarers International Research Centre, School of Social Sciences, Wales

Cardiff, UK

e-mail: acejoi@cf.ac.uk
} 
has evolved. The challenges impinging on meaningful shipboard experiences for Filipino seafarers are discussed.

Filipino seafarers currently estimated at around 215,500 comprise the second largest share in the global maritime industry (BIMCO 2015). Bangko Sentral ng Pilipinas (2016) estimates that $21 \%$ of the annual total cash remittances received from abroad, comprising US\$ 5.572 billion, is contributed to the nation by seafarers. As international seaborne shipments remain an important force for most economies worldwide, the significance of Filipino seafarers, both globally and locally, grows. Filipino seafarers' representation in the seafaring workforce is roughly divided into officers (34\%) and ratings (66\%) (BIMCO 2015). In today's merchant fleet, multinational crewing has become the norm and English is recognised as the language of the sea. In the Philippines where the system of education utilizes English as a medium of instruction, Filipino seafarers are better positioned to capture opportunities in the seafaring profession than their counterparts in China and Russia, for example. The active participation of the Philippine government in terms of promoting seafaring as a career likewise helps bolster Filipino seafarers' dominance in the sea-going labour market.

\section{Trends in Seafaring in the Philippines}

In the 1960s the number of Filipino seafarers working on board international vessels was estimated to be around 2000 and by 1975 this had jumped to 23,534 and continued to show a steady increase (McKay 2007) with an upsurge in the number of seafarers occurring in the late 1980s indicating a sixfold increase (see Table 9.1). Since 1987, the Philippines has consistently been the leading supplier of seafarers worldwide. ${ }^{1}$ In the 2003 Global Labour Market Survey by the Seafarers International Research Centre, about $28.1 \%$ of seafarers are Filipinos, comprising the highest proportion, according to nationality. In the survey, $72 \%$ worked as ratings and the rest were senior (9\%) and junior officers (19\%).

The global presence of Filipino seafarers has to be understood in an historical context and this includes the migration processes that have characterized Filipino society and helped constitute migration and working abroad as an accepted part of life. The development of international labour migration in the Philippines started during the Spanish era, was ingrained during US rule, and was institutionalised from the 1970s onwards. Crucial contributory factors were the American legacy such as the opportunity for seafaring work in the US fleet, the emergence of English as a widely-spoken language following the American occupation together with the development of a relatively advanced educational system; the role of the

\footnotetext{
${ }^{1}$ As quoted in http://www.ilo.org/global/about-the-ilo/newsroom/features/WCMS_219974/lang\% 2D\%2Den/index.htm.
} 
Table 9.1 Number of Filipino seafarers, 1960-2013

\begin{tabular}{l|r}
\hline Year & Number \\
\hline 1960 & 2000 \\
\hline 1975 & 23,534 \\
\hline 1980 & 57,000 \\
\hline 1984 & 50,604 \\
\hline 1985 & 52,290 \\
\hline 1987 & 54,697 \\
\hline 1988 & 67,042 \\
\hline 1989 & 85,913 \\
\hline 1990 & 103,280 \\
\hline 1995 & 111,212 \\
\hline 2000 & 165,401 \\
\hline 2005 & 198,324 \\
\hline 2010 & 306,297 \\
\hline 2013 & 347,150 \\
\hline 2014 & 367,166 \\
\hline 2015 & 401,826 \\
\hline 2016 & 406,531 \\
\hline
\end{tabular}

Sources: Adapted from McKay (2007), POEA various years

government; the economic downturn due to the world oil crisis in the 1970s, and the subsequent deregulation of the shipping industry.

\section{The Rise of Contractual Work and Developments in the Shipping Industry}

The emergence of a global demand for labour encouraged the development of temporary and contract-based migration flows. The initially opportunistic response of the Philippine government in the 1970s to ease local economic pressures and adapt to the global changes became a long-term strategy for development and growth. Structural changes in the shipping industry also made it suitable as an alternative source of overseas employment for Filipino workers. Developments in sea trade, such as the growth of open registers from around the 1950s (Alderton and Winchester 2002) emphasised seafaring's potential as an income source. Under the open register system, nationally registered ships could be registered or re-flagged in another country. Such registers are commonly known as Flags of Convenience (FOC) (Lillie 2004; Stopford 2008). The global oil crisis of the 1970s led to more FOC-registered ships, which allowed for the development of multinational crewing (Sampson 2013). Consequently a global labour market for seafarers emerged (Winchester et al. 2006) and the shipping industry has emerged as the most globalised of all economic activities. (Couper et al. 1999, p. 9). 
In such a deregulated, globalised environment, it became more cost-effective for ships to recruit seafarers from different parts of the world. The Filipinos, whose primary exposure to this trade had been through the US Navy, were now able to work beyond military-related operations and in the merchant fleet. As Filipino seafarers continue to face complex issues concerning their position, participation and prospects, understanding their shipboard lives will illuminate the many ways they grapple with changes occurring not only at the global scale but also at the level of day to day operations on board.

The seafarers in this study were interviewed in two primary sites: in a town in the province of Iloilo and on board a container ship. In the community of Sta. Ana, Iloilo, a total of 49 seafarers' wives were interviewed of whom ten were with their partners as couples. The community in Iloilo was chosen because of its high number of seafaring households. The shipboard fieldwork aboard a container ship, Manuelita, lasted for 41 days (i.e. 30 March to 10 May 2009). All 25 seafarers on the ship participated in the study. There were three nationalities on board: Filipino, Indian and Sri Lankan. Out of 25 seafarers, there were 14 Filipinos, ten Indians and one Sri Lankan. In terms of rank, among the 12 officers, there was one Filipino second mate, a Sri Lankan third mate and a Filipino electro cadet while the rest were Indians. Of the 13 ratings, one was Indian while the rest were Filipinos.

\section{Shipboard Life}

Life on the ship can be likened to life within a total institution to the extent that there is an overlap between life and work and the ship is isolated from the wider society. Shipboard life embodies a strongly routinized occupational culture. According to Lane (2002, p. 101), such characteristics of seagoing vessels' provides the necessary, but not sufficient, conditions for a high level of social cohesiveness and professional competence'. While this allows the shipboard society to operationally function, seafarers' social and domestic life remains subject to a bureaucratic authority. Such restrictions mean that learning to cope with isolation and confinement as part of 'the everyday' constitutes the totalness of the shipboard routine (Gould 2010).

The occupational hierarchy on board defines work roles within a time-conscious and fast-paced work flow. The captain's authority and power allows him/her ${ }^{2}$ direct control of the ship's operations including the living conditions of the crew. Although the chief engineer has the same rank, his/her role mainly revolves around engine concerns. The highest authority in the shipboard chain of command is the captain, also known as the ship's 'master' who oversees various departments (deck, engine and catering). The quality of work dynamics and socialization among crew members is largely influenced by the captain's manner of exercising authority as he is in charge overall (Sampson 2013).

\footnotetext{
${ }^{2}$ Seafarers are overwhelmingly men (see Kitada's discussion in Chap. 6).
} 
As a result of various developments in the shipping industry and the pursuit of cost cutting, there has been a reduction in the numbers of crew on ships to such an extent that 'crew sizes at the turn of the century were reduced from approximately 40-50 per ship to 20-30' for the same sized vessels (Couper et al. 1999, p. 11). The recent technological innovations, in terms of containerisation and fast vessel turnaround, can be seen to have negatively affected the ratings more than the officers. For example in their study of a modern container terminal Sampson and Wu (2003) describe how reduced time in port and remote ports locations have the overall effect of confining ratings to the ship in both physical and social terms. The ship that I sailed on stayed in port no more than 2 days. The combined effects of reduced turnaround times and the smaller numbers of seafarers may be said to have contributed to job enlargement and the imposition of relentless routines which see seafarers being increasingly bound to the work role on board, with little time for a social life or leisure.

\section{Language and Communication}

As mentioned earlier, it has become increasingly common to find seafarers of different national backgrounds working together. Within the diversity found in present-day merchant vessels, English is recognised as the language of the sea and is an essential requirement for seafarers. This entails having communicative competence, using the appropriate vocabulary, phrases and intonation in operational and social contexts found on board. Sampson and Zhao (2003), in considering data from 14 multilingual ships, highlight the need for English proficiency in crew members. A variety of issues relating to the importance of communication to the working environment have been raised in other studies on board multicultural ships such as effective implementation of health and safety on board (Kahveci et al. 2002; Bhattacharya 2009) and social involvement relating to satisfaction and morale on the ship (Sampson and Thomas 2003).

Overall, on board Manuelita, seafarers reported being able to interact effectively however they identified certain challenges pertaining to safety-critical operations. A second engineer recalled how he would ensure that commands issued to engine trainees were properly followed:

He is a bit new. So whenever I use certain terms, maybe he is not able to understand so I repeat it for two or three times more. When he says 'okay, I know now', that is when I know he understood me. But, I would still send fourth engineer to go and see what he is doing. (Second Engineer, Interview 155)

In adopting the standards of the current ship, the trainee's knowledge and techniques had to conform to specific performance measures. Part of learning by experience involved being able to display a functional proficiency in clarifying procedures involved in a particular task. While using a shared language was critical for coordinating tasks, the acquisition of a variety of communication strategies (such 
as repetition of instructions and sign language) helped avoid misunderstandings and ensured that work was carried out properly.

In adapting to the work environment, professionally and personally, willingness to learn cut across nationality. Being aware of such dynamics, seafarers modified their manner of communicating and often avoided a polarised view of certain nationalities' work ethics. In this way they were able to concentrate on creating working relationships that accepted and valued diversity. Such awareness is crucial because not only does it influence how people are perceived but also the extent to which they are treated with respect, support and self-reflection. Adopting a more sensitive approach than that which relies on stereotypical assumptions enabled seafarers to be more effective, particularly in supervising ratings from different nationality backgrounds. A conscious choice to avoid the labelling of a particular nationality group facilitated good interactions.

For newcomers on the ship, learning the 'communication' ropes may not be straightforward owing to the fact that they encounter different accents and ways of speaking. Aboard Manuelita, there were two seafarers who were relatively new to working on board ships. One of them was having difficulty in understanding the job orders issued by the second engineer, who was an Indian officer. He mentioned that in trying to grasp some of the words spoken to him, he had to rely on context clues in carrying out tasks. He stressed that:

It's hard if you are new or if you come from a different ship type as you have to adjust to words you have never heard before in your line of work. (Engine Trainee, Ship, Interview 136)

Experience has shown that it is especially important for new crew members to make initial connections with others on board so as to become familiar with the language of the ship. Given the work-focused setting on board, the language used is primarily to convey information and issue commands. In dealing with communication breakdowns, most of the ratings on board the ship resort to what Kahveci and Sampson (2001) refer to as pidgin English which is stylistically consistent with other seafarers' patterns of speech. As one Filipino rating recounted:

When you speak using grammatically constructed English, it becomes difficult for them to be understood. So they learn how to break it up so others get what they mean. (Fieldnotes 5 April 2009)

In this case, the rating's adaptation of his language to his work environment necessitated learning how to vary speech patterns and hence 'speak' like the others. Observing conventional manners in speaking involves not only technical know-how but also the 'ability to penetrate accents and indeed to understand new and particular forms of English' (Kahveci and Sampson 2001, p. 51 in citing Butler 1999). Knowledge of this kind of maritime English allows seafarers to strengthen their work involvement, integrate with others on board and avoid isolation.

Because the learning process takes time, new recruits often struggle with understanding and adapting to seafaring jargon. 
I feel different. Various people that you see, languages that you use. There are times you don't understand each other. Really need to adjust. (OS, Interview 139 Julius)

The multinational context within which seafarers self-consciously operate requires a firm grasp of the language since communication is quite crucial on board in both operational and social contexts. An effective grasp of the English language accompanied with technical knowledge was considered very relevant to work performance. While this may indeed be true, Sampson and Zhao (2003) have shown that proficiency in standardised Maritime English is, to some degree, insufficient as it focuses on resolving job-related issues rather than facilitating informal interactions. The work-centred use of English may have social consequences such as engendering feelings of social estrangement amongst seafarers.

\section{Coping and Enduring: Socialization on Board}

Hierarchy determines not only the structure of roles but also the social order on board. While its organizational function creates conditions of responsibility and compliance, its social currency in terms of developing smooth relations among seafarers poses a barrier. High-ranking seafarers, whether senior or junior officers, seldom mingle with ratings except during informal occasions. Social breaks in the routine of the voyage usually depend on the master's initiative due to the dominance of work schedules. Crewing patterns on a ship also exert an influence on whether social interaction is encouraged or restrained. Sampson (2013) has described how vessels crewed by two or three nationalities may be more socially divided than those with multiple nationalities on board. This was the experience of the seafarers aboard Manuelita with interaction becoming confined according to nationality. In this case numerous ways of coping or 'making do' were employed to ease the socially restrictive environment on board. One of these was humour.

In the stressful, busy situation characteristically found on a ship, humour can be effective in lightening the atmosphere. An exchange of witticisms allows seafarers to cope with daily monotony and job tensions. This makes a difference to how others get through their work, as one rating stated:

It makes the work more bearable. You don't suffer and you get through it happily. (Ablebodied seaman, Ship, Interview 145)

He mentioned that he and the Indian deck cadet had been ordered to wash the bridge floor thoroughly by the chief mate and while they were cleaning the bridge he teased the deck cadet about whether he could do it faster than usual. The ability to make such jokes breaks the ice with other seafarers and is a sign of adaptability towards workmates. It becomes an effective tool in establishing a seafarer's presence on board as it conveys the idea of a crew member attuned to the ship's internal workings. In the process, it also becomes part of the natural coping mechanism that connects crew members when on board. 
When there was conflict amongst the Filipino ratings regarding the kind of 'bossy' management style practised by the bosun, he was called lolo or grandfather as a reference to his old age.

Sometimes in the morning you can hear not so nice words from him. We just smile. Then call him lolo. He doesn't know that. (Ordinary Seaman, Ship, Interview 140)

Of course, they all refrained from insulting the bosun when he was around. For instance, when the bosun was a few minutes late one of the ratings asked, 'Where is lolo?' The collective manner in which the other Filipino seafarers connected with this joke could be seen at the moment when the bosun appeared-all of them automatically changed the topic and discussed something else. Even the engine ratings at the table nearby took the cue and immediately discussed other topics. The use of the word 'lolo' became a way for the ratings to express contempt without being judged as insubordinate. This was what Noon and Blyton (1997) described as the 'informal triumphing over the formal' (Douglas 1975). The same situation was identified by Collinson (2002, p. 270) among shop floor workers. In that case, joking was the manual workers' way of 'coping with deskilled, high pressure and/or physically dangerous work'. As the bosun decided to stand by his way of instilling discipline, the tensions that remained were ameliorated through humour in order to emphasize tacitly his unfair approach.

This strategy enabled all the ratings to share some form of connection with each other. Although the ratings from the engine department did not usually work under the direction of the bosun, their annoyance about the bosun's tendency to monitor their beer consumption when in the lounge was a source of tension. Hence, the act of joining in the laughing whenever a 'grandfather' joke was brought up revealed their agreement with its accompanying undertones as they shared and empathized with the group's general feeling. Although laughing with the group indicates one form of subtle resistance to domination and control, it also reinforces the sense of belonging amongst the ratings. The entertaining critical look at the bosun, albeit momentary, provided a way to enact social cohesion. As succinctly expressed by Noon and Blyton (1997, pp. 159-160): 'joking at work plays an important regulatory function by providing a means of expression that assists group cohesion, deflects attention from the dehumanizing aspects of work and acts to preserve the existing power hierarchy'.

Although humour can be useful in forming cohesion in a group, it can have the opposite effect when not properly executed. Newcomers on board learned that funny stories were only amusing when used in a particular context or when expressed according to accepted boundaries. An electro-cadet shared his story on how he sensed a negative reaction from a joke he made about stray dogs with one of his superiors:

I mentioned how in our area, if your dog gets into the neighbours' place then it is no longer yours. (Electro-cadet, Ship, Interview 134)

The awkward silence following the supposedly witty remark hinted that such an attitude towards eating dogs was not considered funny. Using humour in the 
workplace required a broad perspective that takes into consideration the position of those at the receiving end. On a ship with different nationalities, funny remarks required sensitivity towards the others' beliefs, traditions and practices. Otherwise, the inappropriate use of humour could further widen and reinforce the isolating conditions on board. Nevertheless, the capacity of humour to bring nationalities together was also manifested:

The Filipino messman acted gay when he saw the Indian engineer and put his arm around him. The other seafarers in the corridor laughed and teased him about it. (Ship Fieldnotes April 2009)

Joking has its risks, especially among multinational crews, but if properly executed can bring seafarers together (Kahveci et al. 2002).

\section{Forming Names}

Just as nationality may create social divisions, it also becomes a way for seafarers of the same nationality to come together using a common language. Amongst Filipino seafarers for instance, the use of localised names for the officers bonded them together. For instance, the captain was called 'tatay' (father) or 'apat' (which means four, and is a reference to the four stripes on his shoulders), the chief engineer was called 'hepe' (chief) while the chief officer, 'kamote' (a pun on scratching the head). Using a different language allowed ratings the freedom to express their viewpoints and to critically discuss certain behaviours of the officers. This was shown in the following instance:

The ship had just left the port and the Filipino ratings were having their dinner. They were chatting freely about the second engineer whom they call hepe. Then suddenly that person passed by the mess hall door. Everyone shared a laugh and someone said out loud, "good thing he can't understand us!" (Fieldnotes 24 April 2009)

The use of Filipino names enabled the Filipino seafarers to freely express their opinions. They could, for instance, criticise the Indian officers without the threat of being reported by the only Indian rating. This was akin to hidden transcripts whereby 'every subordinate group creates... a hidden transcript that represents a critique of power spoken behind the back of the dominant' (Scott 1985).

More often than not, this strategy was used when gossiping about the officers' peculiarities. The messman for instance revealed that:

We talk about this officer on board who went on a shore leave and stayed out for a long time.

We thought, he couldn't be just by himself! (Fieldnotes 7 May 2009)

There was this engine officer who requested rolls of tissue paper so many times per month that he exceeded what is allowed. We think that he might have taken some of that home. . or maybe used them for something else. We talk about that. (Fieldnotes 7 May 2009)

Through this mechanism they developed and sustained strategic acts of resistance. The use of a common language gave them the chance to refer to those in 
power without fear of risking their position. Lawrence and Robinson (2007) refer to the 'disparity between need for autonomy and an experienced loss of freedom' as a potential contributor to frustration in the workplace. Use of the Filipino language gave them a sense of privacy so that:

They wouldn't know they are being talked about. (Ordinary Seaman, Ship, Interview 140).

It made for them an avenue to vent their disappointments about work or share stories about past seafaring experiences or even refer to current news about the Philippine government or their families in a relaxed atmosphere. The versatility of using the local language somehow recouped some of the curtailed freedom on board.

\section{Tales of Threats and Revenge}

Most of the stories of threats and revenge by Filipino seafarers are surrounded by myths on exacting well-deserved vengeance on abusive officers. These are passed on from one seafarer to another and from one ship to another and often come to the fore in threatening situations. When asked about the desirable qualities of an officer at work, most of them referred to respect as very important in their work environment. Lack of respect, they said, could actually push them to commit extreme actions. One deck rating cited the situation that occurred in the engine department when the engine ratings were not granted their holiday entitlements. He empathized by referring to possible ways in which he could inflict revenge if pushed to extremes:

If you are really angry at one person then you can create trouble for him. For me, say I am angry at the chief mate, I can go to the ballast room and just push on those buttons that can create trouble. Say, nobody saw me, then who will be blamed? Him! Or his computer, I can destroy all his files. Right? I can get back at him. (Able-bodied Seaman, Ship, Interview 142)

Conveying their grievance by referring to their capacity for sabotage not only highlighted the importance of the holiday entitlement but also underscored the need to retain their sense of worth when unfairly treated. In addition, given the large number of Filipino seafarers on board, this also underlined the potential for such events to happen.

Consequently, they would occasionally refer to myths regarding revenge successfully achieved by others, such as:

There is one crew member who got some mighty adhesive and glued the lock in the captain's suitcase so it couldn't be opened. There is also one who was thrown overboard with stones on his body... (Able-bodied Seaman, Ship, Interview 142)

By diminishing the inherent power of those in position, seafarers were able to reassure themselves that not only was this done on board the ship but that others have gone through it and therefore shared the same view. The perspective put forward by Morrill, Zald and Rao regarding social spaces in organisations aptly referred to the creation of an autonomous social space in which 'subordinates spin tales of revenge, celebrate hero myths of those who stood up to exploitive superiors and engage in 
discourses that underscore the inherent dignity of subordinates' (2003, p. 398) Moderating the degree of dominance by their superiors through the act of sharing stories of revenge creates a way for them to reinforce their common view and re-establish their potential for togetherness in unfavourable situations.

Overall, resistant strategies show how group cohesion is reinforced while at the same time emphasising how Filipino seafarers develop awareness of themselves functioning as one nationality. The potentiality for divisiveness reveals how it can be isolating for all crew members if social togetherness becomes constrained according to nationality. By simultaneously consenting to and resisting authority, Filipino ratings adjust the boundaries of their social space on board in order to cope with the tensions arising from such conditions.

\section{Conclusion}

As a result of the shipping industry becoming internationalized, globalized and deregulated, Filipino seafarers aboard merchant vessels increasingly find themselves working alongside those from different nationalities. In achieving cooperation, team effort and socially fulfilling relationships are highlighted as crucial to seafarers' daily shipboard life and having a good command of the English language provides confidence in interacting with the crew, suggesting a good capacity for teamwork. This however comes with various challenges such as communicating effectively within a multicultural environment and avoiding stereotype-based biases in dealing with other nationalities. Fluency in the English language including maritime jargons and phrases help seafarers, particularly the new ones, integrate within the strong occupational context of the ship. Officers tasked with managing the crew are better able to adopt management practices that value diversity at work and avoid stereotyping certain nationalities. Such a level of cultural awareness is helpful in integrating seafarers in the ship in terms of re-establishing and strengthening their work involvement and avoiding isolation.

The nationality mix on a ship affects the social order on board. For ships with two nationalities where officers belong to one nationality and ratings belong to another, it may become more difficult for the crew to get together informally. The nationalitydivide and the division by hierarchy can be seen as mutually reinforcing. As the ratings' feelings of being overpowered are magnified, the seafarers form small groups (according to their nationality) to dissipate such threats. Conjuring a resistant space by way of humour and tales can serve to circumvent the resulting labour insecurities. As recounted previously, without the support of certain key officers, achieving genuine inclusion on board, in the sense of having a 'happy ship', presents a challenge. 


\section{References}

Alderton, T., and N. Winchester. 2002. Globalisaton and De-Regulation in the Maritime Industry. Marine Policy 26: 35-43.

Bangko Sentral ng Pilipinas. 2016. Overseas Filipinos' Remittances [online] URL: Accessed February 18, 2018. [www.bsp.gov.ph/statistics/keystat/ofw2.htm]

Bhattacharya, S. 2009. The Impact of the ISM Code on the Management of Occupational Health and Safety in the Maritime Industry. PhD Thesis, Cardiff University.

BIMCO. 2015. Manpower Report The global Supply and Demand for Seafarers in 2015 International Chamber of Shipping. London: Maritime International Secretariat Services Limited.

Butler, S. 1999. A View on Standards in South-East Asia. World Englishes 18 (2): 187-198.

Collinson, D. 2002. Managing Humour. Journal of Management Studies 39 (3).

Couper, A., et al. 1999. Voyages of Abuse: Seafarers, Human Rights and International Shipping. London: Pluto.

Douglas, M. 1975. Implicit Meanings. Essays in Anthropology. London: Routledge.

Ellis, N., and H. Sampson. 2003. The Global Labour Market for Seafarers Working Aboard Merchant Cargo Ships 2003. Cardiff: SIRC.

Gould, E. 2010. Towards a Total Occupation: A Study of UK Merchant Navy Officer Cadetship. $\mathrm{PhD}$ Thesis, Cardiff University.

Kahveci, E., and H. Sampson. 2001. Findings from the Shipboard Based Study of Mixed Nationality Crews. In SIRC, Seafarers International Research Centre Symposium 2001: Proceedings of SIRC'S second symposium held at Cardiff University. [Online] [Accessed September 24, 2016] Cardiff, Seafarers International Research Centre (SIRC) Cardiff University.

Kahveci, E., T. Lane, and H. Sampson. 2002. Transnational Seafarer Communities. Cardiff: Seafarers International Research Centre.

Lane, T. 2002. Social Order of the Ship in a Globalised Labour Market for Seafarers. In Changing Forms of Employment: Organisations, Skills and Gender, ed. Rosemary Crompton, Duncan Gallie, and Kate Purcell. London, New York: Routledge.

Lawrence, T., and S. Robinson. 2007. Ain't Misbehavin: Workplace Deviance as Organizational Resistance. Journal of Management 33 (3): 378-394.

Lillie, N. 2004. Global Collective Bargaining on Flag of Convenience Shipping. British Journal of Industrial Relations 42 (1): 47-67.

McKay, S. 2007. Filipino Sea Men: Identity and Masculinity in a Global Labor Niche. In Asian Diasporas: New Formations, New Conceptions, ed. R. Parrenas and L.C.D. Siu, 61-83. Stanford: Stanford University Press.

Morrill, C., M.N. Zald, and H. Rao. 2003. Covert Political Conflict in Organizations: Challenges from Below. Annual Review of Sociology 29: 391-415.

Noon, P., and M. Blyton. 1997. The Realities of Work. Basingstoke, Hampshire: Macmillan Press Houndmills.

Sampson, H. 2013. International Seafarers and Transnationalism in Twenty-First Century. Manchester: Manchester University Press.

Sampson, H., and M. Thomas. 2003. Lone Researchers at Sea: Gender, Risk and Responsibility. Qualitative Research 3 (2): 165-189.

Sampson, H., and B. Wu. 2003. Compressing Time and Constraining Space: The Contradictory Effects of ICT and Containerisation on International Shipping Labour. International Review of Social History 48: 123-152.

Sampson, H., and M. Zhao. 2003. Multilingual Crews: Communication and the Operation of ships. World Englishes 22 (1): 31-43. ISSN 08832919.

Scott, J. 1985. Weapons of the Weak: Everyday Forms of Peasant Resistance. Yale University Press.

Stopford, M. 2008. Maritime Economics. 3rd ed. London: Routledge.

Storgård, J., N. Berg, and O-P. Brunila. 2013. Insight in Ships Crews. Multiculturalism and Maritime Safety. Proceedings of the International Scientific Meeting on Corporate Social 
Responsibility (CSR) in Shipping. ed. V. Kunnaala, and J. Viertola. 2nd International Maritime Incident and Near Miss Reporting Conference (IMISS 2013). 11-12 June 2013, Kotka, Finland. Publications of the Centre for Maritime Studies University of Turku, A71.

Winchester, N., H. Sampson, and T. Shelly. 2006. An Analysis of Crewing Levels: Findings from the SIRC Global Labour Market Study. SIRC: Cardiff University. ISBN: 1-900174-27-8.

Open Access This chapter is licensed under the terms of the Creative Commons Attribution 4.0 International License (http://creativecommons.org/licenses/by/4.0/), which permits use, sharing, adaptation, distribution and reproduction in any medium or format, as long as you give appropriate credit to the original author(s) and the source, provide a link to the Creative Commons licence and indicate if changes were made.

The images or other third party material in this chapter are included in the chapter's Creative Commons licence, unless indicated otherwise in a credit line to the material. If material is not included in the chapter's Creative Commons licence and your intended use is not permitted by statutory regulation or exceeds the permitted use, you will need to obtain permission directly from the copyright holder. 